\title{
Multi-walled carbon nanotubes complement the anti-tumoral effect of 5-Fluorouracil
}

\author{
Eloisa González-Lavado ${ }^{1}$, Lourdes Valdivia ${ }^{1}$, Almudena García-Castaño³, Fernando \\ González ${ }^{1}$, Carmen Pesquera ${ }^{1}$, Rafael Valiente ${ }^{1,2}$ and Mónica L. Fanarraga ${ }^{1}$ \\ ${ }^{1}$ Grupo de Nanomedicina, IDIVAL-Universidad de Cantabria, 39011, Santander, Spain \\ ${ }^{2}$ Dpto. Física Aplicada, Facultad de Ciencias, Universidad de Cantabria, 39011, Santander, Spain \\ ${ }^{3}$ Unidad De Ensayos Clínicos, Oncología Médica y Medicina Paliativa, Hospital Valdecilla-IDIVAL 39011, Santander, Spain \\ Correspondence to: Mónica L. Fanarraga, email: fanarrag@unican.es \\ Keywords: nanomaterial; nanocarrier; drug delivery; combined therapy; microtubule dynamics \\ Abbreviations: CNTs: Carbon nanotubes; MWCNTs: multi-walled nanotubes; 5-FU: 5-Fluorouracil; TGA: thermogravimetric analysis; \\ TEM: Transmission electron microscopy
}

Received: January 31, $2019 \quad$ Accepted: February 19, $2019 \quad$ Published: March 12, 2019

Copyright: González-Lavado et al. This is an open-access article distributed under the terms of the Creative Commons Attribution License 3.0 (CC BY 3.0), which permits unrestricted use, distribution, and reproduction in any medium, provided the original author and source are credited.

\section{ABSTRACT}

Multiple-drug resistance in human cancer is a major problem. To circumvent this issue, clinicians combine several drugs. However, this strategy could backfire resulting in more toxic or ineffective treatments. Carbon nanotubes (CNTs), and particularly multi-walled nanotubes (MWCNTs), display intrinsic properties against cancer interfering with microtubule dynamics and triggering anti-proliferative, antimigratory and cytotoxic effects in vitro that result in tumor growth inhibition in vivo. Remarkably, these effects are maintained in tumors resistant to traditional microtubule-binding chemotherapies such as Taxol ${ }^{\circledR}$.

In the view of these properties, we investigate the use of MWCNTs in the development of active-by-design nanocarriers, attempting to enhance the effect of broadly-used chemotherapies. We compare the cytotoxic and the anti-tumoral effect of 5-Fluorouracil (5-FU) -an antimetabolite treatment of various forms of cancer- with that of the drug physisorbed onto MWCNTs. Our results demonstrate how the total effect of the drug 5-FU is remarkably improved ( $50 \%$ more effective) when delivered intratumorally coupled to MWCNTs both in vitro and in vivo in solid tumoral models. Our results demonstrate how using MWCNTs as anti-cancer drug delivery platforms is a promising approach to boost the efficacy of traditional chemotherapies, while considerably reducing the chances of resistance in cancer cells.

\section{INTRODUCTION}

Most of the localized tumors are satisfactorily treated with surgery. Unfortunately, most aggressive cancers metastasize to distant organs and develop resistance to chemotherapy. For this reason, clinicians often need to combine different drugs to simultaneously interrupt cell proliferation pathways at various points, boosting the potential cytotoxic effect of the treatment. Regrettably, anti-cancer drug combination does not always work. For instances, Taxol $^{\circledR}$ (paclitaxel) and 5-Fluorouracil (5-FU) inhibit different and complementary mechanisms in cancer cell proliferation but, they have been reported to interfere with each other, questioning the clinical use of this drug combination parenterally [1]. As an alternative, drug co-encapsulation has also been suggested as a possible way to increase the therapeutic response of the $\mathrm{Taxol}^{\circledR}+5$-FU mixture [2]. Here, we propose a new alternative to boost the chemotherapeutic effect of 5-FU with nanomaterials which intrinsically display antitumoral properties, interfering with cell proliferative mechanisms thus, complementing the cytotoxic effect of the drug.

Carbon nanotubes (CNTs) have shown excellent properties and applications in nanobiotechnology [3-5]. 
In particular, multi-walled CNTs (MWCNTs) can penetrate most biological barriers and infiltrate inside cells where they display unique biomimetic properties with the intracellular cytoskeletal polymers, mostly with microtubules [6]. These tubulin polymers, that are traditional targets for many anticancer therapies [7], share many properties with MWCNTs. Both self-assemble, have similar dimensions, are exceptionally resilient, and show comparable physical properties (for example, shear stress, bending stiffness and Young's modulus) [6]. Their similarities prompt interaction in vitro [8] and in vivo [9], and the assemblage mixed functional bio-synthetic tubulin polymers that display an enhanced stability compared to conventional microtubules [10]. The increased stability of these mixed polymers causes critical changes in the cellular biomechanics, triggering the reported antiproliferative $[9,11]$, anti-migratory [12-14] and cytotoxic effects in vitro in cancer cells [15-17], and significant antitumoral effects in vivo $[18,19]$. In addition, some studies show how MWCNTs are effective in cells and tumors that have developed resistance to $\operatorname{Taxol}^{\circledR}[18]$. Thus, the microtubule-stabilizing effect of Taxol $^{\circledR}$-that binds a structural pocket in the $\beta$-tubulin polypeptide- could be significantly boosted when combined with MWCNTs, for these nanomaterials utilize an alternative microtubule stabilization mechanism, complementary to that $\mathrm{Taxol}^{\mathbb{}}$ [10]. Summarizing, these results support the potential use of MWCNTs as anti-tumoral agents exclusively based on their intrinsic properties, using novel cytotoxic mechanisms.

But despite these numerous advantages, the stigma of the structural similarity of CNTs with asbestos fibers has slowed down progress of these nanomaterials in medicine, and have been repeatedly excluded in the design of drug nanocarriers [20]. Fortunately, the recent discovery of a series of surface treatments that make MWCNTs more biocompatible and bio-degradable by phagocytic cells, has opened many new opportunities in nanomedicine [21-27]. It is now known that macrophages in vitro can degrade surface-oxidized MWCNTs in few days, reducing the length of the nanotubes in approximately $30 \%$, and in vivo, in the tumoral tissue after triggering significant antitumoral effects [19]. Here we investigate the possibility of enhancing the effect for traditional cancer drugs using MWCNTs as nanocarrier adjuvant systems. For the study we have loaded MWCNTs with 5-FU, a routine broadly used anticancer drug that inhibits cell replication mostly in the "S" phase of the cell cycle, complementing the intrinsic microtubule dynamics inhibitory effect of MWCNTs during mitosis (Figure 1).

\section{RESULTS AND DISCUSSION}

\section{Characterization of the 5-FU physisorption on MWCNTs and in vitro drug release}

Simple molecular physisorption via $\pi$-stacking has been broadly used for successful loading of different drugs onto graphene and MWCNTs preventing drug inactivation due to the binding procedure (Figure 2A) [28, 29]. In this study, we have physisorbed 5-FU on MWCNTs (5-FUMWCNTs) as described in the methods section. The amount of the physisorbed 5-FU was estimated using thermogravimetric analysis (TGA). Figure $2 \mathrm{~B}$ shows the TGA analysis where approximately $3 \%$ of the total mass of the 5-FU-MWCNT sample corresponds to the drug. This data was further corroborated using fluorescence spectroscopy analysis as a complementary technique (Supplementary Figures 1-2). This analysis served to verify the calculated amount of ca. $3 \mathrm{mg}$ of 5-FU per $100 \mathrm{mg}$ of MWCNTs $(3 \% \mathrm{w} / \mathrm{w})$. Hence, this data will be considered in the comparative studies that follow.

5-FU release from the 5-FU-MWCNTs was first evaluated in vitro. For this purpose, 5-FU-MWCNTs were

\section{Working hypothesis of the additive effect against cancer}
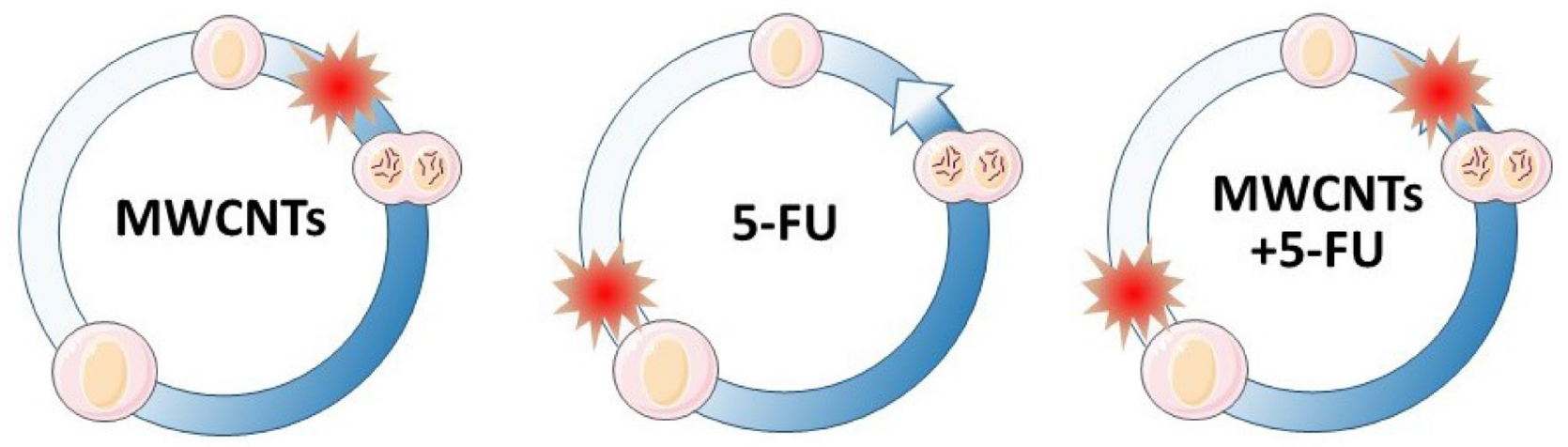

Figure 1: Cell cycle MWCNTs and 5-FU blockage points. (left) MWCNTs typically interfere with the mitosis process. (center) 5-FU blocks the cell cycle at the "S" phase, during DNA and organelle replication. (right) Sequential and complementary blockage points of MWCNTs and 5-FU therapies. The expected double blockage of the cell cycle should inhibit cancel cell growth more intensively. 
exposed to physiological conditions (phosphate buffer $\mathrm{pH}$ $=7.4$ at $37^{\circ} \mathrm{C}$ ) during $140 \mathrm{~h}$. Measurement of the collected samples using fluorescence spectroscopy suggested an initial phase of 'burst' release of the drug during the first $24 \mathrm{~h}$, that corresponded to a $40-42 \%$ of the loaded 5-FU. This was followed by a 'sustained release' phase where the rest of the drug was slowly discharged in the course of several days (Supplementary Figure 3).

\section{Boosted anti-proliferative and cytotoxic effects to 5-FU when administered on MWCNTs}

To evaluate the effect of the 5-FU loaded MWCNTs in vitro, we exposed HeLa cell cultures to: $3 \mu \mathrm{g} / \mathrm{mL}$ of the plain drug; $100 \mu \mathrm{g} / \mathrm{mL}$ of pristine MWCNTs (p-MWCNTs); and finally, to $100 \mu \mathrm{g} / \mathrm{mL}$ of 5 -FUMWCNTs. The effects of the treatments were compared $72 \mathrm{~h}$ after exposure to the three therapies.
Both, the resuspended 5-FU and 5-FU-MWCNTs produced a potent anti-proliferative effect accompanied by an obvious increase in the cellular size compared to untreated controls, or to cells treated with p-MWCNTs. This phenotype suggested a possible blockage in the "S" part of the cell cycle (Figure 3). Remarkably, cultures treated with 5-FU-MWCNTs appeared more severely affected that those treated with the free drug or p-MWCNTs.

Quantification of the cellular area in cultures treated with both, 5-FU and 5-FU-MWCNT, revealed a statistically significant 3-fold increase in cell size compared to untreated or p-MWCNTs controls (Supplementary Figure 4). As previously reported for MWCNTs [9], cells treated with 5-FU loaded onto MWCNTs also displayed characteristic long and thin cytoplasmic extensions resulting of the biomimetic interaction between MWCNTs with the cytoskeletal
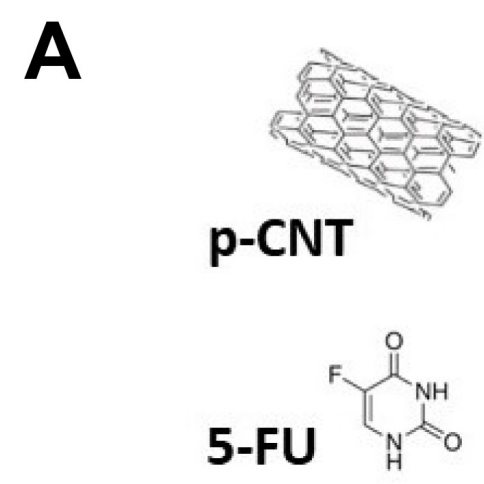

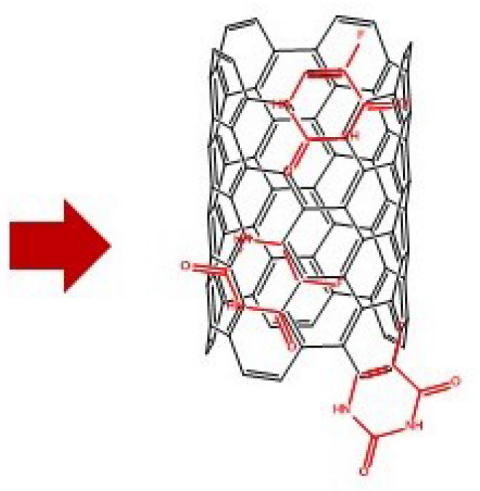

5FU-CNT

\section{B}

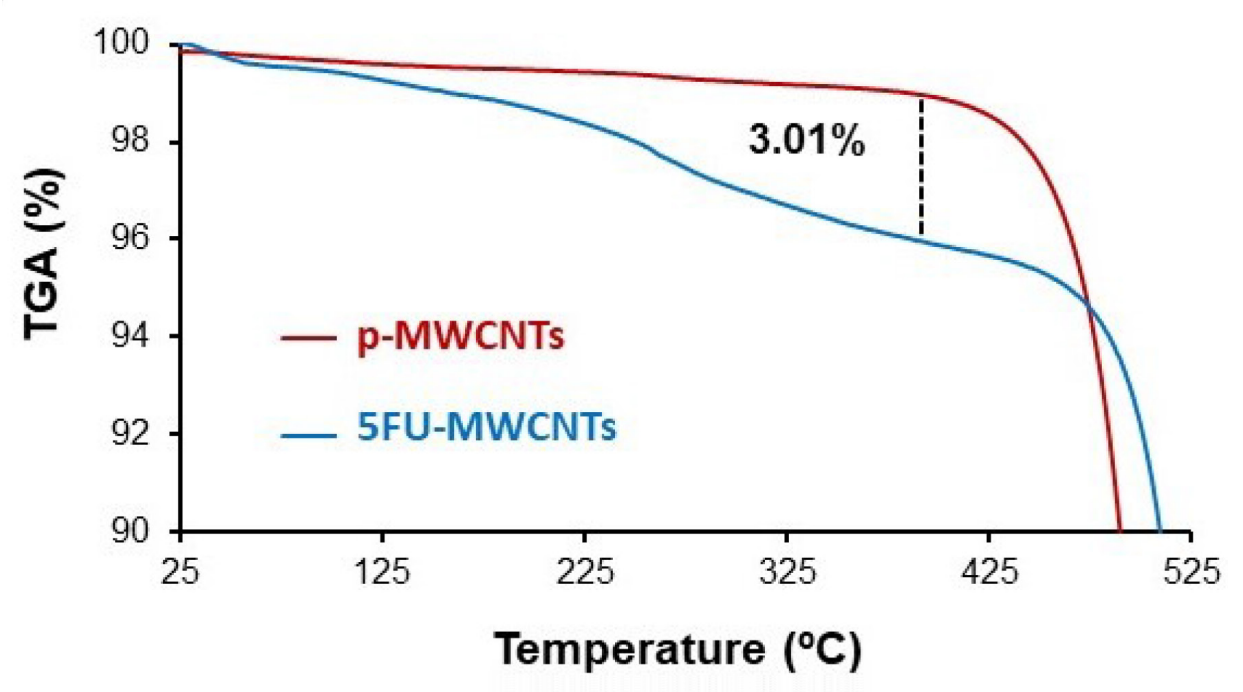

Figure 2: Characterization of the 5-FU-MWCNTs. (A) Representative diagram of the interaction between CNTs and 5-FU. (B) TGA corresponding to p-MWCNTs and 5-FU-MWCNTs samples under air atmosphere. An approximate 3\% mass loss corresponding to the physisorbed 5-FU is calculated. 
microtubules (Figure 3, solid arrows, Supplementary Figure 4). In addition, these cultures also presented the expected low surviving cellular rate. The abundance of cells with patent signs of apoptosis (empty arrows) supported the efficiency of this cytotoxic treatment in vitro and suggested a significant rise in the efficacy of the drug when applied decorating MWCNTs.

\section{A double cell cycle blockage to intensify the therapeutic effect}

To perform an accurate qualitative and quantitative analysis of the cytotoxic effects of the treatment, we used flow cytometry. This statistically powerful technique allows the characterization of the cell cycle for each condition, and to quantify the percentage of apoptotic cells in approximately 10,000 cells per experiment. For the study we used human HeLa cells and murine B16F10 cells. This murine model of malignant melanoma cells is resistant to many traditional chemotherapeutic drugs [30] and, as the majority of melanomas, displays an aggressive nature, being genetically heterogeneous and highly metastatic [31].

Figure 4 illustrates the proportion of live cells (blue) vs. dead cells (red) for untreated controls and for the 3 different treatments: p-MWCNTs, 5-FU, and 5-FUMWCNTs. These data reveal a significant blockage in the " $\mathrm{S}$ " phase, $72 \mathrm{~h}$ post-treatment typical of 5-FU for both, HeLa and melanoma cells. More interestingly, both cell lines showed higher sensitivity to the cytotoxic effect of the 5-FU-MWCNTs compared to the plain drug. Cytotoxicity in cells treated with standard 5-FU was 14\% and $17 \%$ for $\mathrm{HeLa}$ and melanoma cells, respectively. Parallel cultures treated with the same amount of 5-FU physisorbed onto MWCNTs displayed 21\% and 27\% cell death, respectively (Figure 4, red). Furthermore, the sum of the cytotoxic effects of 5-FU and the p-MWCNTs separately were less than the effect of the 5-FU-MWCNTs $(4 \%+14 \%<21 \%$ for HeLa, $9 \%+17 \%<27 \%$ for the melanoma cells). These results suggest that, at least in vitro, MWCNTs increase the effectiveness of the drug while significantly amplifying the cytotoxic effect of the two chemotherapies individually applied. Therefore, data indicate that the sequential inhibitory effect of the 5-FU at the "S" phase and the MWCNTs at the "M" phase of the cell cycle, as depicted in Figure 1, could be complementary.

\section{A significantly enhanced in vivo effect of 5-FU- MWCNTs compared to 5-FU}

The anti-tumoral effect of 5-FU-MWCNTs was also tested on solid melanoma tumours produced by transplantation of B16-F10 cells. This system model is
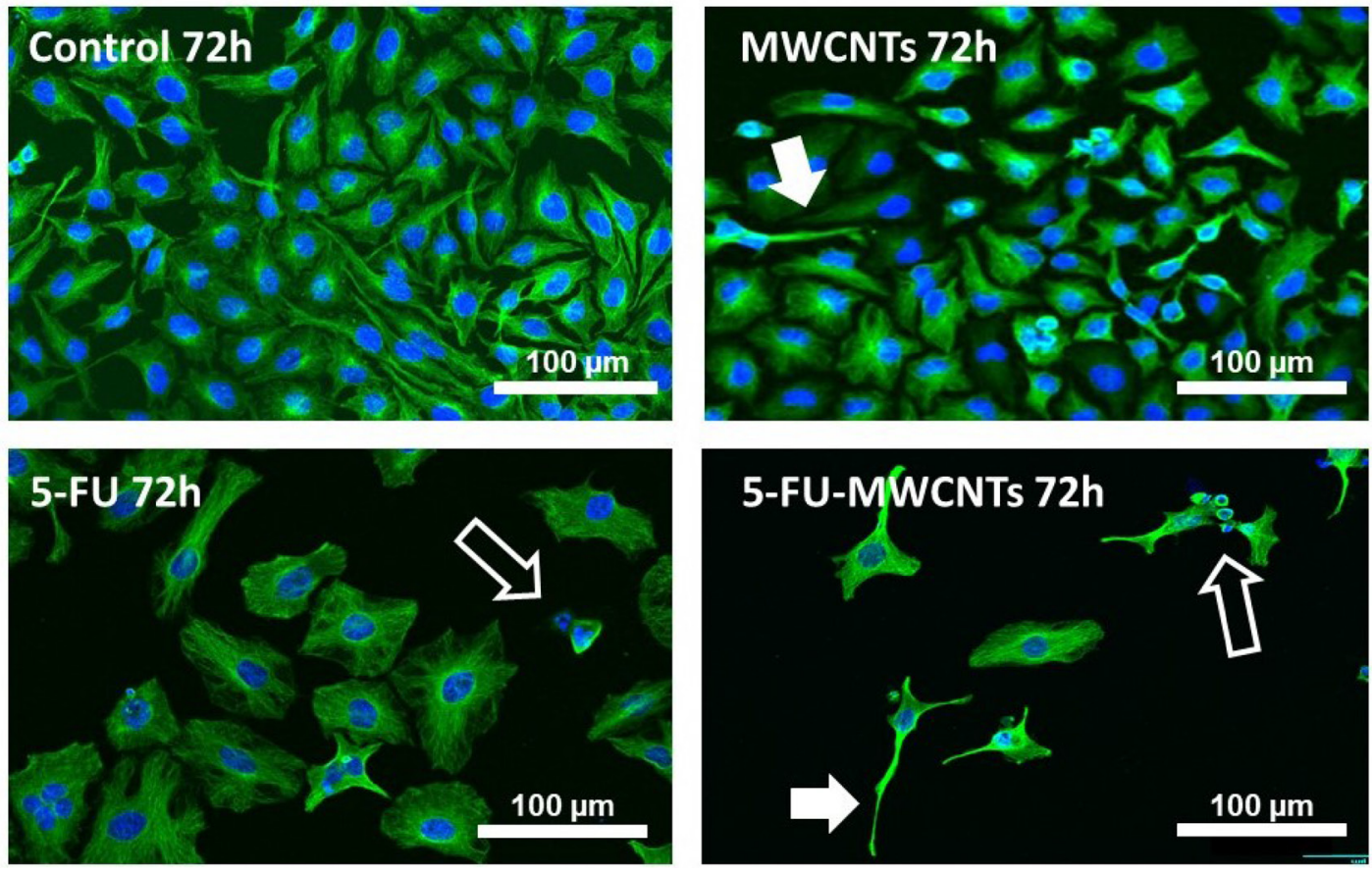

Figure 3: Anti-proliferative and cytotoxic effect of 5-FU-MWCNTs in vitro. Confocal microscopy images of HeLa displaying the microtubule network (green channel) and nuclei stained with Hoechst (blue channel). Cells were either untreated (control) or exposed to $100 \mu \mathrm{g} / \mathrm{mL}$ p-MWCNTs, $3 \mu \mathrm{g} / \mathrm{mL} 5$-FU or $100 \mu \mathrm{g} / \mathrm{mL}$ 5-FU-MWCNTs. Treatment with the plain drug triggered a patent increase in the cell size and patent anti-proliferative effects in the cultures. Cells treated with identical amounts of 5-FU loaded on MWCNTs displayed an enlarged size and apparent magnification of 5-FU anti-proliferative effects. As typical for MWCNTs, some cells also presented long cellular extensions resulting of bundled microtubules (solid arrows). Cells dying by apoptosis are also observed (empty arrows). 
highly representative of most malignant tumours, being characterized by local acidosis, edema and abundant tumor-associated supporting stromal cells that include macrophages [32]. As in previous studies, solid pigmented melanoma tumours were treated only once to improve reproducibility, with either 5-FU-MWCNTs $(2 \mu \mathrm{g})$ or the controls, namely: (i) the control resuspension media (Figure 5, supernatant), (ii) resuspended p-MWCNTs $(2 \mu \mathrm{g})$, or (iii) the free drug (identical amount as those supported on the $2 \mu \mathrm{g}$ of MWCNTs). For direct comparison, injections were performed in littermates, in a total population of more than 200 mice. All mice were sacrificed 4 days post-treatment for analysis.

Results shown in Figure 5 demonstrate how 4 days after a single treatment with 5-FU-MWCNTs there was an important reduction of the tumor mass. Tumors treated intratumorally with the plain drug or p-MWNCTs were reduced compared to controls but were significantly larger than those treated with de 5-FU physisorbed onto MWCNTs. Compared to the control treatment, tumoral masses were almost half the size when treated with 5-FU-MWCNTs. This effect was significantly improved respect to that triggered by the plain drug or plain p-MWCNTs. The later also demonstrated a patent tumoral growth inhibitory effect confirming previously reported data [17]. Summarizing, these experiments served to conclude that the important antitumoral effect observed for the 5-FU loaded onto MWCNTs -reducing in ca. $60 \%$ the tumoral mass- results of the complementary cytotoxic mechanisms generated by the two therapies, interfering with two different steps of the cancer cell proliferative cycle, as originally hypothesized in Figure 1.

\section{MATERIALS AND METHODS}

\section{Materials}

High-purity ( $>98 \%$ ) MWCNTs were obtained from Sigma Aldrich (Ref. 698849). The as-produced MWCNTs were washed with $\mathrm{HCl}$ to remove impurities, resuspended in distilled water by sonication and incubated with a solution of ca. $10 \mathrm{mg} / \mathrm{mL}$ 5-FU (Accord, Ref. 603544.3). The mixture was stirred in a vertical wheel at ca. 20 r.p.m. for $2 \mathrm{~h}$ at room temperature, centrifuged at 12000 $\mathrm{g}$ and washed with distilled water three times in repeated cycles of centrifugation (12000 g, $5 \mathrm{~min}$ )/redispersion (Supplementary Figure 1).

The concentration of the physisorbed 5-FU was estimated using fluorescence spectroscopy as described in the Supplementary Material (Supplementary Figures 1-2). TGA was carried out in a TG-DSC Setaram Model Setsys Evolution 1750 in air atmosphere. Data were processed with the Quadstartm 422 software ( $\mathrm{T}$ ramp $10.00^{\circ} \mathrm{C} / \mathrm{min}$ to $830.00^{\circ} \mathrm{C}$ ). 5-FU-Release assays were performed in PBS $(\mathrm{pH}=7.4)$ at $37^{\circ} \mathrm{C}$. Released 5-FU was measured using fluorescence spectroscopy in an Edinburgh Inst. FLSP-920 using the calibration line of Supplementary Figure 2.

\section{Cell culture and confocal microscopy imaging}

HeLa cells were grown in cultured with Eagle's Minimum Essential Medium (BiowhittakerTM). Cells were fixed with $4 \%$ paraformaldehyde for imaging. DNA was stained with Hoechst dye (from SigmaAldrich $\left.^{\circledR}\right)$. Microtubules were immunostained with B512 anti- $\alpha$-tubulin antibody $\left(\right.$ Sigma-Aldrich $\left.^{\circledR}\right)$ and a
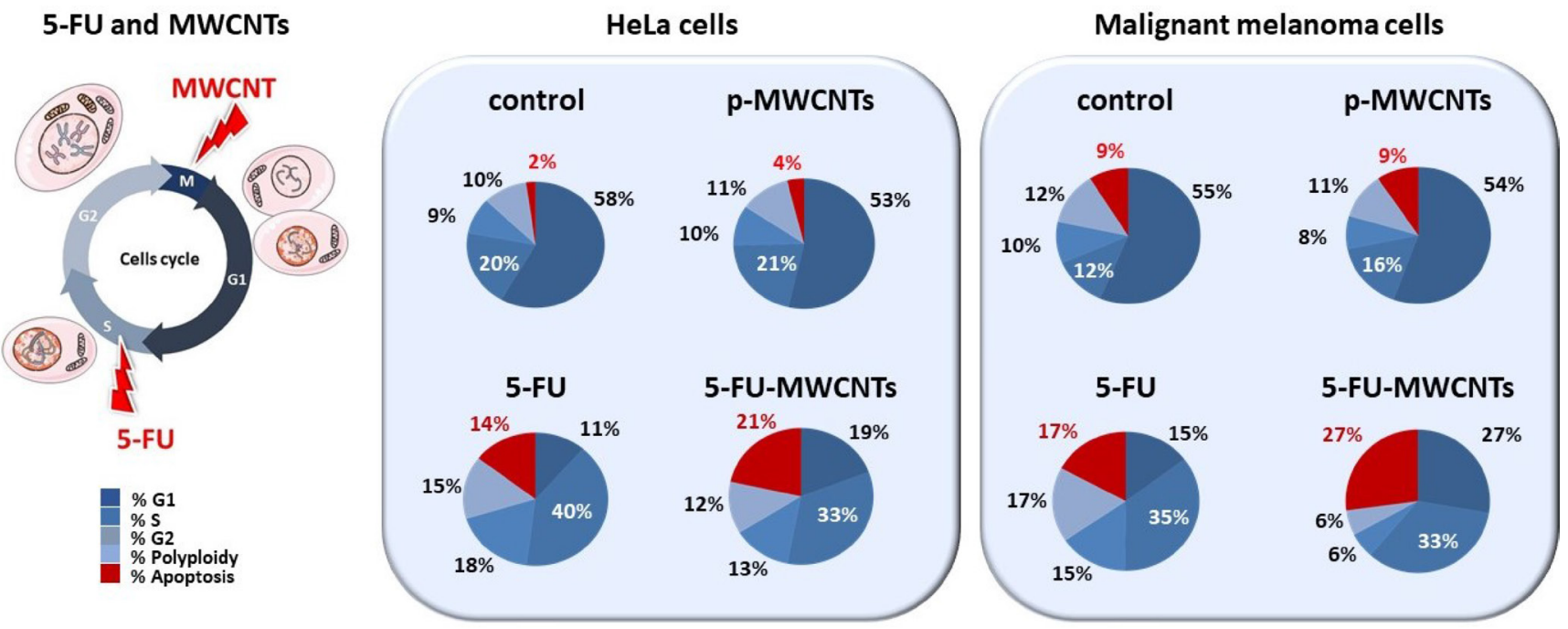

Figure 4: Quantification of the cytotoxic effect of 5-FU-MWCNTs compared to controls. Cultures of HeLa and malignant melanoma cells were exposed to p-MWCNTs, soluble 5-FU or 5-FU-MWCNTs during $72 \mathrm{~h}$ and were compared to untreated controls. Flow cytometry quantitative analysis demonstrates that the cytotoxic effect of the 5-FU when administered as 5-FU-MWCNT is significantly enhanced in both, human and murine cancer cells (represented in red). Cell cycle changes evidence a patent blockage in the "S" phase for both, 5-FU and 5-FU-MWCNTs treatments (indicated with white lettering). 
secondary goat anti-mouse Alexa Fluor 488-conjugated IgG (Molecular probes ${ }^{\circledR}$ ). Confocal laser scanning and phase contrast images were obtained with a Nikon A1R confocal microscope. Image processing was performed with the NIS-Elements Advanced Research software. All fluorescent images are pseudo-colored.

\section{Tumor studies in vivo}

Tumorigenesis was induced by subcutaneous transplantation of a total of $2 \times 10^{5}$ B16-F10 murine melanoma cells in $10 \mu \mathrm{L}$ of culture medium containing antibiotics following previously described protocols $[18,19,32]$. Animal experimentation procedures were performed according to EU legislation in accordance with the Guidelines for 'Care and Use of Laboratory Animals' of The University of Cantabria and were approved by the local Animal Ethics Committee. Solid pigmented tumours were single treated 7 days post-transplant with a unique intratumoral dose of $2 \mu \mathrm{g}$ of nanotubes resuspended in a volume of $10 \mu \mathrm{L}$ of culture medium. Parallel experiments comparing the effect of 5-FU-MWCNTs, pristine MWCNTs (p-MWCNTs), 5-FU (using equivalent calculated amounts) or resuspension media -as an excipient control- were performed. To reduce natural artefacts, litters were divided in two halves and were injected in parallel with two of the former compositions. Tumours masses were carefully dissected and weighed 4 days post injection for quantitative statistical analyses. Total number of animals are indicated in the text and figure.

\section{Flow cytometry and electron microscopy imaging}

Flow cytometry studies were carried out on a suspension of fixed cells stained with Hoechst using a
Becton Dickinson FACS CantoII equipment. This dye produces a quantitative staining of DNA that allows the determination of changes in the cell cycle and cell proliferation blockage, permitting DNA fractional quantification ("sub-G1/G0" peak) indicative of apoptosis. Three different replicas of the experimental analysis were performed on an average of 10,000 cells per condition using the FACS Diva software (Becton Dickinson). For illustrative purposes the original flow cytometry graphs have been substituted by pie charts displaying the calculated proportions of the different cell populations, including apoptotic cells in Figure 4. Transmission Electron Microscopy (TEM) was performed in a JEOL JEM 2100 operated at $120 \mathrm{kV}$ on ethanol-dispersed samples adsorbed onto a Lacey copper grid.

\section{Statistical analyses}

A Student's two-tailed $t$-test was used for statistical analysis and to evaluate significance that was stablished for a $\left(^{*}\right) p=0.05$ or a $\left(^{* *}\right) p=0.01$. The confidence levels and total number of events included in the study $(n)$ are indicated in the figure legends. Quantitative results are expressed as mean values with their corresponding standard error bars.

\section{CONCLUSIONS}

The emergence of drug resistance depends on the genetic instability, heterogeneity and high mutational rate of tumour cells among others. Malignant cancer cells continuously develop new mechanisms of resistance to chemotherapy that include drug destruction, selection of mutations that inhibit drug
A

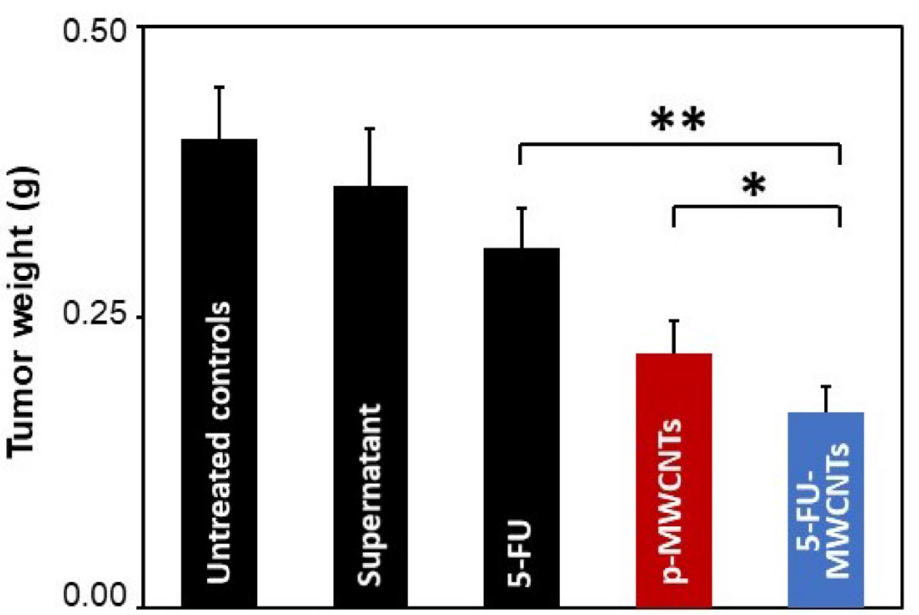

B
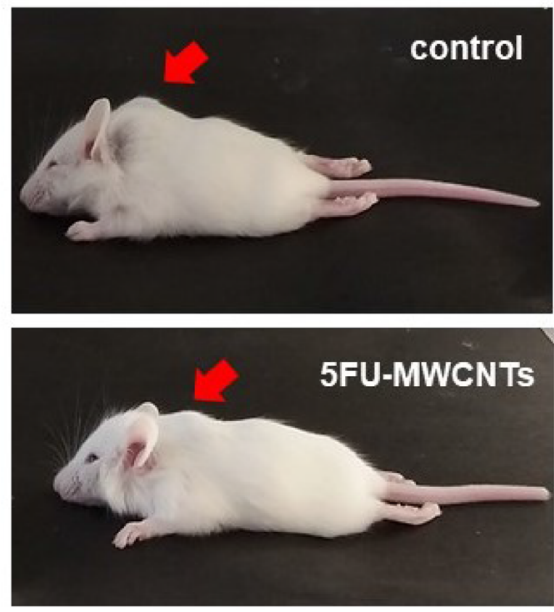

Figure 5: In vivo 5-FU-MWCNTs effects in solid melanoma tumours. (A) Statistical evaluation of the average tumoral weight $96 \mathrm{~h}$ post-treatment (single injection containing $2 \mu \mathrm{g}$ of p-MWCNTs, 5-FU-MWCNTs or identical amounts of the 5-FU drug). 5-FUMWCNTs trigger a statistically significant anti-tumoral effect respect to 5-FU injected locally $\left(t=3.6, n=75,{ }^{* *}=t_{99}\right)$ or tumours treated with plain p-MWCNTs $\left(t=1.31, n=87,{ }^{*}=t_{975}\right)$. (B) Representative mouse littermates bearing solid melanoma tumours $96 \mathrm{~h}$ after a single intra-tumoral injection of a control resuspension medium or 5-FU-MWCNTs. Arrows point at the tumour location. 
binding to targets, drug efflux out of the cells, etc. The administration of chemotherapy loaded onto MWCNT used as nanocarriers can significantly improve many different aspects of the traditional chemotherapy. On one hand, the penetrating properties of these nanomaterials are interesting when considering, for instances, treatments applied topically, where CNTs can penetrate and spread into the affected lesion transporting the drug away from the application point. But more interestingly, MWCNTs have intrinsic antitumoral properties that can be exploited in cancer treatment interfering with microtubule dynamics, triggering effects similar to traditional drugs such as $\mathrm{Taxol}^{\circledR}$ (paclitaxel) or Epothylones. Indeed, the fact that MWCNTs can produce notable antitumoral effects in solid tumours generated by Taxol $^{\circledR}$-resistant cells suggests these nanofilaments can complement and significantly boost chemotherapy. Here we demonstrate how drug and nanomaterial therapies can complement each other, in vitro and in vivo in the treatment of cancer. In conclusion, these data invite to improve anticancer delivery systems considering the use of nanomaterials with intrinsic antitumoral properties as active excipients, to enhance the therapeutic effect of traditional chemotherapy, preventing drug resistance in cancer.

\section{ACKNOWLEDGMENTS}

We are grateful to Profs. M. Prato and T. Torroba for their discussion, to Débora Muñoz for the technical help, and to Drs M. Barrejón and Z. Sygiannis for their technical advice. We also want to thank the Institute IDIVAL and the UC for the support to EGL, and to the MINECO for FPU fellowship to LVF.

\section{CONFLICTS OF INTEREST}

The authors declare no conflicts of interest.

\section{FUNDING}

This work was founded by the following sources: Spanish MINECO, Instituto de Salud Carlos III, the European Union FEDER funds under Projects ref. PI16/00496 (AES 2016), MAT2015-69508-P, NanoBioApp Network (MINECO-17-MAT2016-81955REDT) European Union (European Regional Development Fund-ERDF) and INNVAL 16/15, INNVAL 17/11.

\section{REFERENCES}

1. Johnson KR, Wang L, Miller MC 3rd, Willingham MC, Fan W. 5-Fluorouracil interferes with paclitaxel cytotoxicity against human solid tumor cells. Clin Cancer Res. 1997; 3:1739-45. [PubMed]
2. Iqbal S, Rashid MH, Arbab AS, Khan M. Encapsulation of Anticancer Drugs (5-Fluorouracil and Paclitaxel) into Polycaprolactone (PCL) Nanofibers and In Vitro Testing for Sustained and Targeted Therapy. J Biomed Nanotechnol. 2017; 13:355-66. https://doi.org/10.1166/jbn.2017.2353. [PubMed]

3. Gong X, Huang D, Liu Y, Peng Z, Zeng G, Xu P, Cheng M, Wang R, Wan J. Remediation of contaminated soils by biotechnology with nanomaterials: bio-behavior, applications, and perspectives. Crit Rev Biotechnol. 2018; 38:455-68. https://doi.org/10.1080/07388551.2017.136844 6. [PubMed]

4. Caetano FR, Felippe LB, Zarbin AJ, Bergamini MF, Marcolino-Junior LH. Gold nanoparticles supported on multi-walled carbon nanotubes produced by biphasic modified method and dopamine sensing application. Sens Actuators B Chem. 2017; 243:43-50. https://doi. org/10.1016/j.snb.2016.11.096.

5. Rivas GA, Rodríguez MC, Rubianes MD, Gutiérrez FA, Eguílaz M, Dalmasso PR, Primo EN, Tettamanti C, Ramírez ML, Montemerlo A, Gallay P, Parrado C. Carbon nanotubes-based electrochemical (bio)sensors for biomarkers. Appl Mater Today. 2017; 9:566-88. https://doi. org/10.1016/j.apmt.2017.10.005.

6. Pampaloni F, Florin EL. Microtubule architecture: inspiration for novel carbon nanotube-based biomimetic materials. Trends Biotechnol. 2008; 26:302-10. https://doi. org/10.1016/j.tibtech.2008.03.002. [PubMed]

7. Jordan MA, Wilson L. Microtubules and actin filaments: dynamic targets for cancer chemotherapy. Curr Opin Cell Biol. 1998; 10:123-30. https://doi.org/10.1016/S09550674(98)80095-1. [PubMed]

8. Dinu CZ, Bale SS, Zhu G, Dordick JS. Tubulin encapsulation of carbon nanotubes into functional hybrid assemblies. Small. 2009; 5:310-15. https://doi.org/10.1002/ smll.200801434. [PubMed]

9. Rodríguez-Fernández L, Valiente R, González J, Villegas JC, Fanarraga ML. Multiwalled carbon nanotubes display microtubule biomimetic properties in vivo, enhancing microtubule assembly and stabilization. ACS Nano. 2012; 6:6614-25. https://doi.org/10.1021/nn302222m. [PubMed]

10. García-Hevia L, Fernández F, Grávalos C, García A, Villegas JC, Fanarraga ML. Nanotube interactions with microtubules: implications for cancer medicine. Nanomedicine (Lond). 2014; 9:1581-88. https://doi. org/10.2217/nnm.14.92. [PubMed]

11. Muller J, Decordier I, Hoet PH, Lombaert N, Thomassen L, Huaux F, Lison D, Kirsch-Volders M. Clastogenic and aneugenic effects of multi-wall carbon nanotubes in epithelial cells. Carcinogenesis. 2008; 29:427-33. https:// doi.org/10.1093/carcin/bgm243. [PubMed]

12. Villegas JC, Álvarez-Montes L, Rodríguez-Fernández L, González J, Valiente R, Fanarraga ML. Multiwalled carbon nanotubes hinder microglia function interfering with cell migration and phagocytosis. Adv Healthc Mater. 
2014; 3:424-32. https://doi.org/10.1002/adhm.201300178. [PubMed]

13. García-Hevia L, Valiente R, Fernández-Luna JL, Flahaut E, Rodríguez-Fernández L, Villegas JC, González J, Fanarraga ML. Inhibition of cancer cell migration by multiwalled carbon nanotubes. Adv Healthc Mater. 2015; 4:1640-44. https://doi.org/10.1002/adhm.201500252. [PubMed]

14. Dong C, Eldawud R, Sargent LM, Kashon ML, Lowry D, Rojanasakul Y, Dinu CZ. Carbon nanotube uptake changes the biomechanical properties of human lung epithelial cells in a time-dependent manner. J Mater Chem B Mater Biol Med. 2015; 3:3983-92. https://doi.org/10.1039/ C5TB00179J. [PubMed]

15. Ding L, Stilwell J, Zhang T, Elboudwarej O, Jiang H, Selegue JP, Cooke PA, Gray JW, Chen FF. Molecular characterization of the cytotoxic mechanism of multiwall carbon nanotubes and nano-onions on human skin fibroblast. Nano Lett. 2005; 5:2448-64. https://doi. org/10.1021/n10517480. [PubMed]

16. Reddy AR, Reddy YN, Krishna DR, Himabindu V. Multi wall carbon nanotubes induce oxidative stress and cytotoxicity in human embryonic kidney (HEK293) cells. Toxicology. 2010; 272:11-16. https://doi.org/10.1016/j. tox.2010.03.017. [PubMed]

17. García-Hevia L, Valiente R, González J, Fernández-Luna JL, Villegas JC, Fanarraga ML. Anti-cancer cytotoxic effects of multiwalled carbon nanotubes. Curr Pharm Des. 2015; 21:1920-29. https://doi.org/10.2174/1381612821666 150302144101. [PubMed]

18. García-Hevia L, Villegas JC, Fernández F, Casafont Í, González J, Valiente R, Fanarraga ML. Multiwalled carbon nanotubes inhibit tumor progression in a mouse model. Adv Healthc Mater. 2016; 5:1080-87. https://doi.org/10.1002/ adhm.201500753. [PubMed]

19. González-Lavado E, Iturrioz-Rodríguez N, Padín-González E, González J, García-Hevia L, Heuts J, Pesquera C, González F, Villegas JC, Valiente R, Fanarraga ML. Biodegradable multi-walled carbon nanotubes trigger antitumoral effects. Nanoscale. 2018; 10:11013-20. https://doi. org/10.1039/C8NR03036G. [PubMed]

20. Marchesan S, Kostarelos K, Bianco A, Prato M. The winding road for carbon nanotubes in nanomedicine. Mater Today. 2015; 18:12-19. https://doi.org/10.1016/j. mattod.2014.07.009.

21. Kagan VE, Konduru NV, Feng W, Allen BL, Conroy J, Volkov Y, Vlasova II, Belikova NA, Yanamala N, Kapralov A, Tyurina YY, Shi J, Kisin ER, et al. Carbon nanotubes degraded by neutrophil myeloperoxidase induce less pulmonary inflammation. Nat Nanotechnol. 2010; 5:35459. https://doi.org/10.1038/nnano.2010.44. [PubMed]

22. Seo W, Kapralov AA, Shurin GV, Shurin MR, Kagan VE, Star A. Payload drug vs. nanocarrier biodegradation by myeloperoxidase- and peroxynitrite-mediated oxidations: pharmacokinetic implications. Nanoscale. 2015; 7:8689-94. https://doi.org/10.1039/C5NR00251F. [PubMed]

23. Shvedova AA, Kapralov AA, Feng WH, Kisin ER, Murray AR, Mercer RR, St Croix CM, Lang MA, Watkins SC, Konduru NV, Allen BL, Conroy J, Kotchey GP, et al. Impaired clearance and enhanced pulmonary inflammatory/ fibrotic response to carbon nanotubes in myeloperoxidasedeficient mice. PLoS One. 2012; 7:e30923. https://doi. org/10.1371/journal.pone.0030923. [PubMed]

24. Farrera C, Bhattacharya K, Lazzaretto B, Andón FT, Hultenby K, Kotchey GP, Star A, Fadeel B. Extracellular entrapment and degradation of single-walled carbon nanotubes. Nanoscale. 2014; 6:6974-83. https://doi. org/10.1039/c3nr06047k. [PubMed]

25. Andón FT, Kapralov AA, Yanamala N, Feng W, Baygan A, Chambers BJ, Hultenby K, Ye F, Toprak MS, Brandner BD, Fornara A, Klein-Seetharaman J, Kotchey GP, et al. Biodegradation of single-walled carbon nanotubes by eosinophil peroxidase. Small. 2013; 9:2721-9. https://doi. org/10.1002/smll.201202508. [PubMed]

26. Elgrabli D, Dachraoui W, Ménard-Moyon C, Liu XJ, Bégin D, Bégin-Colin S, Bianco A, Gazeau F, Alloyeau D. Carbon nanotube degradation in macrophages: live nanoscale monitoring and understanding of biological pathway. ACS Nano. 2015; 9:10113-24. https://doi.org/10.1021/ acsnano.5b03708. [ [PubMed]

27. Nunes A, Bussy C, Gherardini L, Meneghetti M, Herrero MA, Bianco A, Prato M, Pizzorusso T, Al-Jamal KT, Kostarelos K. In vivo degradation of functionalized carbon nanotubes after stereotactic administration in the brain cortex. Nanomedicine (Lond). 2012; 7:1485-94. https:// doi.org/10.2217/nnm.12.33. [PubMed]

28. Sun X, Liu Z, Welsher K, Robinson JT, Goodwin A, Zaric $\mathrm{S}$, Dai H. Nano-Graphene oxide for cellular imaging and drug delivery. Nano Res. 2008; 1:203-12. https://doi. org/10.1007/s12274-008-8021-8. [PubMed]

29. Liu J, Cui L, Losic D. Graphene and graphene oxide as new nanocarriers for drug delivery applications. Acta Biomater. 2013; 9:9243-57. https://doi.org/10.1016/j. actbio.2013.08.016. [PubMed]

30. Hart IR, Raz A, Fidler IJ. Effect of cytoskeleton-disrupting agents on the metastatic behavior of melanoma cells. J Natl Cancer Inst. 1980; 64:891-900. [PubMed]

31. Poste G, Doll J, Hart IR, Fidler IJ. In vitro selection of murine B16 melanoma variants with enhanced tissue-invasive properties. Cancer Res. 1980; 40:1636-44. [PubMed]

32. García-Hevia L, Fernández F, Casafont I, Villegas JC, Fanarraga ML. A fast, reliable and cost-effective method to generate tumor organs for therapy screening in vivo. Biomed Phys Eng Express. 2016; 2:035009. https://doi. org/10.1088/2057-1976/2/3/035009. 